\title{
Computing Bond Values to Teach Time Value of Money Principles
}

\author{
Carl B. McGowan ${ }^{1} \&$ Donald T. Joyner ${ }^{2}$ \\ ${ }^{1}$ Norfolk State University, USA. \\ Correspondence: Carl B. McGowan, Jr., AFMIS, Norfolk State University, Norfolk, VA 23507, USA.
}

Received: March 31, 2015

Accepted: April 8, 2015

Available online: June 5, 2015

doi:10.11114/afa.v1i2.862

URL: http://dx.doi.org/10.11114/afa.v1i2.862

\begin{abstract}
The objective of this paper is to demonstrate how to use bond valuation to teach students how to use a financial calculator. In this paper, a single bond issuance is examined using three different yields to maturity (i.e. market rates). The present values of a $\$ 1000$ bond issue, valued with five years to maturity and a ten percent coupon rate, are determined using three different yields to maturity: $8 \%$ (which would result in a premium), $10 \%$ (which would result in neither a discount nor a premium), and $12 \%$ (which would result in a discount). The present value of the bond is determined by calculating the present values of both the coupon payment stream (an annuity) and the maturity value (present value of a lump sum) given three different situations. All three values are determined for each year as the time to maturity decreases. A discount (premium) from a change in the YTM is reduced each year until maturity. The results are shown in tables and graphed in Figure 2.
\end{abstract}

Keywords: Time value of money, bond valuation, premium bond, discount bond

\section{Introduction}

A bond is a long-term promissory note sold by a company in which the company agrees to make periodic interest payments and return the face value of the bond at a pre-specified time. The indenture is the written agreement between the corporation selling the bonds and the lender who buys the bonds that details all of the terms of the issue. Preparing an indenture is a highly legal and time-consuming process. As a result, the yield to maturity in effect at the time the bond is issued, doesn't always match the yield to maturity in effect at the time of the indenture. Rather than re-write the indenture, the initial bond price is adjusted to match the current yield to maturity in effect at the time of issuance. These take the forms of a premium or discount. The bond rate is fixed and does not change. Consequently, the price of the bond will fluctuate in subsequent trading depending on the bond rate in relation to changing current yield to maturity rates. The basic terms of the bonds are the face value of the bond, the coupon rate, the coupon payments, and the maturity date of the bond. With these basic terms it is possible to value a bond. ${ }^{1}$

Basic Terms of Bonds

Face value - the maturity value of a bond

Coupon payment - the interest payment of the bond

Coupon rate - the interest rate paid on the face value of the bond

$\mathrm{CP}=\mathrm{CR}(\mathrm{FV})$

Maturity - the date when the principal amount of the bond is repaid

Yield to maturity - the required rate of return on a bond

Bonds are long-term, fixed return financial securities. Bond interest payments are a fixed obligation of the firm and the failure to make an interest payment or bond refunding payment constitutes a technical default and if not corrected, bondholders and other creditors can force the firm into bankruptcy. The cash flow time line for a bond, Figure 1, shows the initial price, the equal annual interest payment, and the bond face value. Given these four variables the current price of a bond can be determined. The coupon payment is the annual (semi-annual) interest payment for the bond. The face value of the bond is the maturity value of the bond. The coupon payment is equal to the face value of the bond times the

1 Most finance and accounting books such as Brigham and Ehrhardt (2008), Damodaran (2006), Ross, Westerfield, and Jordan (2008), and Warren, Reeve, and Duchac (2012) discuss bond valuation and time value of money. 
coupon rate, which is the stated interest rate of the bond. The maturity date is the date when the principle amount of the bond is repaid. The yield to maturity of the bond is the required rate of return for the bond. Since it is the required rate of return, the yield to maturity is often referred to as the market rate of a bond. It represents the interest rate investors expect, given a certain set of circumstances.

Figure 1. Bond Valuation Example and Time Line

Time 5_ $4 \_3 \_2 \_1 \_0$

Cash PriceCP $\quad \mathrm{CP} \quad \mathrm{CP} \quad \mathrm{CP} \quad \mathrm{CP}+\$ 1000$

The Indenture is the written agreement between the corporation and the lender detailing the terms of the debt issue. The basic terms of the bond issue specifies the face value of the bond, the coupon rate of the bond from which the coupon payment is derived, and the maturity date of the bond. The indenture is printed on the reverse side of the bond. Typically, most bonds are in electronic as opposed to physical form. The individuals who own the bonds are tracked electronically.

There are additional features for bonds. The indenture specifies whether the bond is registered or bearer. The ownership of a registered bond is recorded at the firm and a lost bond can be replaced. Ownership of a bearer bond is not recorded and a lost bond cannot be replaced. Bearer bonds are rarely used in the United States due to legislation enacted in the early 1980's to curb money laundering. The indenture specifies the total amount of bonds issued. A bond may be a mortgage bond or a debenture. A mortgage bond is secured specific property described in the indenture. A debenture is not secured and the claims of a subordinated debenture are subordinated to other creditors. Debenture bonds are backed by the full faith and credit of the corporation issuing the bonds. The financial strength of the company as well as its past credit history, are determinants of the cost of its borrowings (i.e. interest rate). Bond rating agencies such as Standard and Poors often assign a credit rating to a corporation. The rating reflects the corporation's ability to repay the bond and interest. The higher the rating, the lower the risk. The lower the rating, the higher the risk. Interest rate is dictated by risk. If a firm has a high $\mathrm{S} \& \mathrm{P}$ rating, it means that they will have to pay less interest than a firm with a low $\mathrm{S} \& \mathrm{P}$ rating. If the risk of default is

A sinking fund provision provides for early repayment or partial repayment of a bond issue. A sinking fund provision protects the bond-holders from default if a bond issue falls due and the bond issuer has not saved the funds to repay the bond issue. Sinking fund provisions may specify specific bonds that will be recalled or randomly select bonds to refund or simply repurchase bonds in the open market. Call provisions allow the bond issuer to refund a bond issue early. If a bond issue is sold with a particularly high coupon rate, the bond issuer will refund the bond issue when they are able to invest at lower interest rates. While this is favorable to the bond issuer, in most cases the bond holders would prefer the corporation not call the bonds because it means they will have to invest at lower interest rates. Occasionally, bond holders anticipate corporations exercising the call option and match the date the option can be exercised to their own liquidity needs. To compensate bondholders for the lower interest rates, the bond issuer pays a call premium usually equal to a year's interest. They may also include a provision that allows for bond holders to convert the bond proceeds into common stock. There is normally a deferral period during which the bond issue may not be recalled.

Additional provisions are called protective covenants that protect the bond-holders from actions on the part of the firm's decision makers which adversely affect the value of the bond issue. For example, the firm may be restricted in future dividend payments. The firm would not be permitted to may a large dividend payment that would leave insufficient funds to cover interest payments. The firm may be restricted future bond issues. This provision protects the existing bondholders from having the value of their bond holdings reduced by the firm increasing leverage to the point where the firm might default. The firm might be limited to a minimum current ratio, protecting the existing bond holders from a liquidity crisis that would lead to default. The current ratio is Current Assets/Current Liabilities. If this ratio is less than one, it would be a clear indication that the firm can't meet current debt obligations. From the viewpoint of the bondholder, the higher the current ratio, the safer the investment. 
The price of a bond is determined by the face value, required rate of return, the stated rate which determines the coupon payment, and the term to maturity. The actual price of the bond is a combination of two calculations. The first item to calculate is the present value of the face amount of the bond which will be paid at the end of the bond term. The second item to calculate is the present value of the series of coupon payments (i.e. annuity). Both present value calculations are based on the current yield to maturity.

\section{Bond Valuation}

The example bond has a face value of $\$ 1000$, a coupon payment of $\$ 100$, a yield to maturity of $10 \%$, and five years to maturity. These values are summarized in Table 1.

Price

Face Value

$\$ 1000$

Coupon Payment

$$
\$ 100=(100 * 0.10)
$$

Required Rate of Return

$$
10 \%
$$

Term to Maturity

5 years

For this bond, the market price is $\$ 1000$. This is the sum of the present value of $\$ 1000$ to be received in 5 years ( $\$ 621$ ) and the present value of 5 interest payments of $\$ 100$ to be received annually (\$379).

Calculate the bond price, if we go forward one time of one year. Now, the term to maturity is only four years.

$\begin{array}{ll}\text { Price } & \\ \text { Face Value } & \$ 1000 \\ \text { Coupon Payment } & 10 \% \\ \text { Required Rate of Return } & (100 * 0.10) \\ \text { Term to Maturity } & 4 \text { years }\end{array}$

When we compute the price of the bond with four years to maturity, the price is $\$ 1000$. This is the sum of the present value of $\$ 1000$ to be received in 4 years $(\$ 683)$ and the present value of 4 interest payments of $\$ 100$ to be received annually (\$317).

Calculate the bond price, if we go forward in time one year. Now, the term to maturity is only three years.

$\begin{array}{ll}\text { Price } & -?+\frac{?}{\$ 1000} \\ \text { Face Value } & \$ 100=(100 * 0.10) \\ \text { Coupon Payment } & 10 \% \\ \text { Required Rate of Return } & \\ \text { Term to Maturity } & 3 \text { years }\end{array}$

When we compute the price of the bond with three years to maturity, the price is $\$ 1000$. This is the sum of the present value of $\$ 1000$ to be received in 3 years $(\$ 751)$ and the present value of 3 interest payments of $\$ 100$ to be received annually (\$249).

Calculate the bond price if we go forward in time one more year. Now, the term to maturity is only two years.

$\begin{array}{ll}\text { Price } & \text { ? } \\ \text { Face Value } & 100=(100 * 0.10) \\ \text { Coupon Payment } & 10 \% \\ \text { Required Rate of Return } & \\ \text { Term to Maturity } & 2 \text { years }\end{array}$

When we compute the price of the bond with two years to maturity, the price is $\$ 1000$. There are only two coupon payments remaining, and the maturity value is discounted one time. The value of the $\$ 1000$ terminal value increases to $\$ 826$ and the value of the one remaining coupons payments drops to $\$ 174$.

Calculate the bond price if we go forward in time one more year. Now, the term to maturity is only one years. Price 


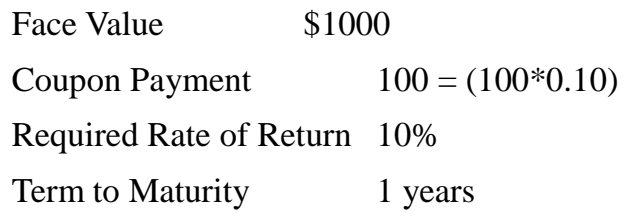

When we compute the price of the bond with one years to maturity, the price is $\$ 1000$. There is only one coupon payment remaining and the maturity value is discounted one time. The value of the $\$ 1000$ terminal value increases to $\$ 909$ and the value of the four remaining coupons payments drops to $\$ 91$.

Table 1. Bond Values for a Bond Selling at Par Value

This first table shows the values computed for the example bond at a $10 \%$ yield to maturity.

\begin{tabular}{|c|c|c|c|c|c|}
\hline Face Value & & 1000 & & & \\
\hline Coupon Rate & & $10 \%$ & & & \\
\hline Years of Maturity & & 5 & & & \\
\hline Discount Rate & & $10 \%$ & & & \\
\hline \multirow[t]{7}{*}{ YTM } & & & $\mathrm{PV}(\mathrm{CP})$ & & \\
\hline & 5 & 621 & & 379 & 1000 \\
\hline & 4 & 683 & & 317 & 1000 \\
\hline & 3 & 751 & & 249 & 1000 \\
\hline & 2 & 826 & & 174 & 1000 \\
\hline & 1 & 909 & & 91 & 1000 \\
\hline & 0 & 1000 & & 0 & 1000 \\
\hline
\end{tabular}

Calculate the bond price if we go forward in time one more year, at maturity. Now, the term to maturity is zero.

$\begin{array}{ll}\text { Price } & ? \\ \text { Face Value } & \$ 1000 \\ \text { Coupon Payment } & \$ 100=(100 * 0.10) \\ \text { Required Rate of Return } & 8 \% \\ \text { Term to Maturity } & 0 \text { years }\end{array}$

When we compute the price of the bond at maturity, the price is $\$ 1000$. There are no coupon payments remaining, and the maturity value is not discounted at maturity. The value of the $\$ 1000$ terminal value increases to $\$ 1000$ and the value of the coupons payments drops to $\$ 0$.

Bond rule number one is that if the bond coupon rate equals the required rate of return, the bond price will be the maturity value. This results regardless of the term to maturity. As the bond nears maturity, the present value of the bond's face value will increase, because it is due sooner and the present value of the bond interest payments will decrease, because the number of interest payments will be fewer. If the required rate of return remains at $10 \%$ for the entire life of this bond, the price will remain at $\$ 1000$. There would never be any need to adjust the price. Price is ultimately determined by the required rate of return. If that rate and the coupon rate are the same, there is no need to adjust the price so that it reflects the required rate of return.

However, assume that the moment that the bond is issued, the required rate of return for a bond with the same risk characteristics as this bond now requires a yield of $8 \%$. Calculate the bond price. These values are summarized in Table 2. Now, the term to maturity is five years.

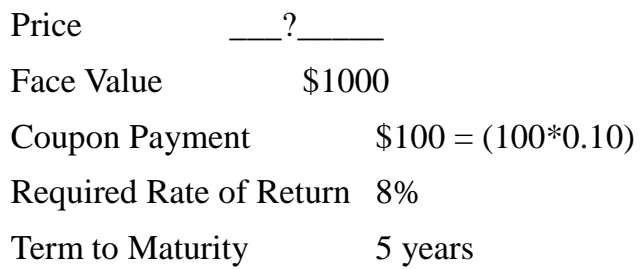

When we compute the price of the bond with an $8 \%$ yield to maturity and five years to maturity, the price is $\$ 1080$. The value of the $\$ 1000$ terminal value is $\$ 681$ and the value of the five coupon payments of $\$ 100$ each is $\$ 399$. The price 
rises from $\$ 1000$ to $\$ 1080$ because bond holders only require an $\$ 80$ per year coupon payment and our bond pays $\$ 100$ coupon per year. Thus, the demand for our bond will rise and the price will increase until the yield to maturity for our bond props from $10 \%$ to $8 \%$.

Calculate the bond price, if we go forward in time one year. Now, the term to maturity is only four years and the required rate of return is $8 \%$.

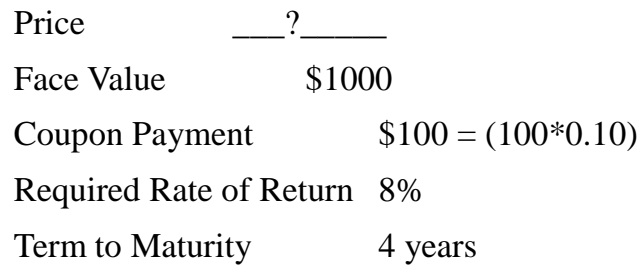

The coupon rate remains fixed at $10 \%$ and the yield to maturity is $8 \%$. When we compute the price of the bond with four years to maturity, the price is $\$ 1066$. Although nothing changed except the term to maturity, the price dropped.

Table 2. Bond Values for a Bond Selling at Par Value. This first table shows the values computed for the example bond at a $10 \%$ yield to maturity.

\begin{tabular}{|c|c|c|c|c|c|c|c|}
\hline Face Value & & & 1000 & & & & \\
\hline Coupon Rate & & & $10 \%$ & & & & \\
\hline Years of Maturity & & & 5 & & & & \\
\hline Discount Rate & & & $8 \%$ & & & & \\
\hline YTM & & PV(1000) & & $\mathrm{PV}(\mathrm{C}$ & & Total & \\
\hline & 5 & & 681 & & 399 & & 1080 \\
\hline & 4 & & 735 & & 331 & & 1066 \\
\hline & 3 & & 794 & & 258 & & 1052 \\
\hline & 2 & & 857 & & 178 & & 1036 \\
\hline & 1 & & 926 & & 93 & & 1019 \\
\hline & 0 & & 1000 & & 0 & & 1000 \\
\hline $\mathrm{PV}$ & & 681 & 735 & 794 & 857 & 926 & 1000 \\
\hline $\mathrm{FV}$ & & 1000 & 1000 & 1000 & 1000 & 1000 & 1000 \\
\hline PMT & & 0 & 0 & 0 & 0 & 0 & 0 \\
\hline$\% \mathrm{I}$ & & 5 & 5 & 5 & 5 & 5 & 5 \\
\hline $\mathrm{N}$ & & 5 & 4 & 3 & 2 & 1 & 0 \\
\hline PV & & 399 & & 31 & 58 & 178 & 0 \\
\hline FV & & 0 & & 0 & 0 & 0 & 0 \\
\hline PMT & & 60 & & 60 & 60 & 60 & 60 \\
\hline$\% \mathrm{I}$ & & 5 & & 5 & 5 & 5 & 5 \\
\hline $\mathrm{N}$ & & 5 & & 4 & 3 & 2 & 0 \\
\hline PV & & 1080 & 1066 & 1052 & 1036 & 1019 & 1000 \\
\hline FV & & 1000 & 1000 & 1000 & 1000 & 1000 & 1000 \\
\hline PMT & & 60 & 60 & 60 & 60 & 60 & 60 \\
\hline$\% \mathrm{I}$ & & 5 & 5 & 5 & 5 & 5 & 5 \\
\hline $\mathrm{N}$ & & 5 & 4 & 3 & 2 & 1 & 0 \\
\hline
\end{tabular}




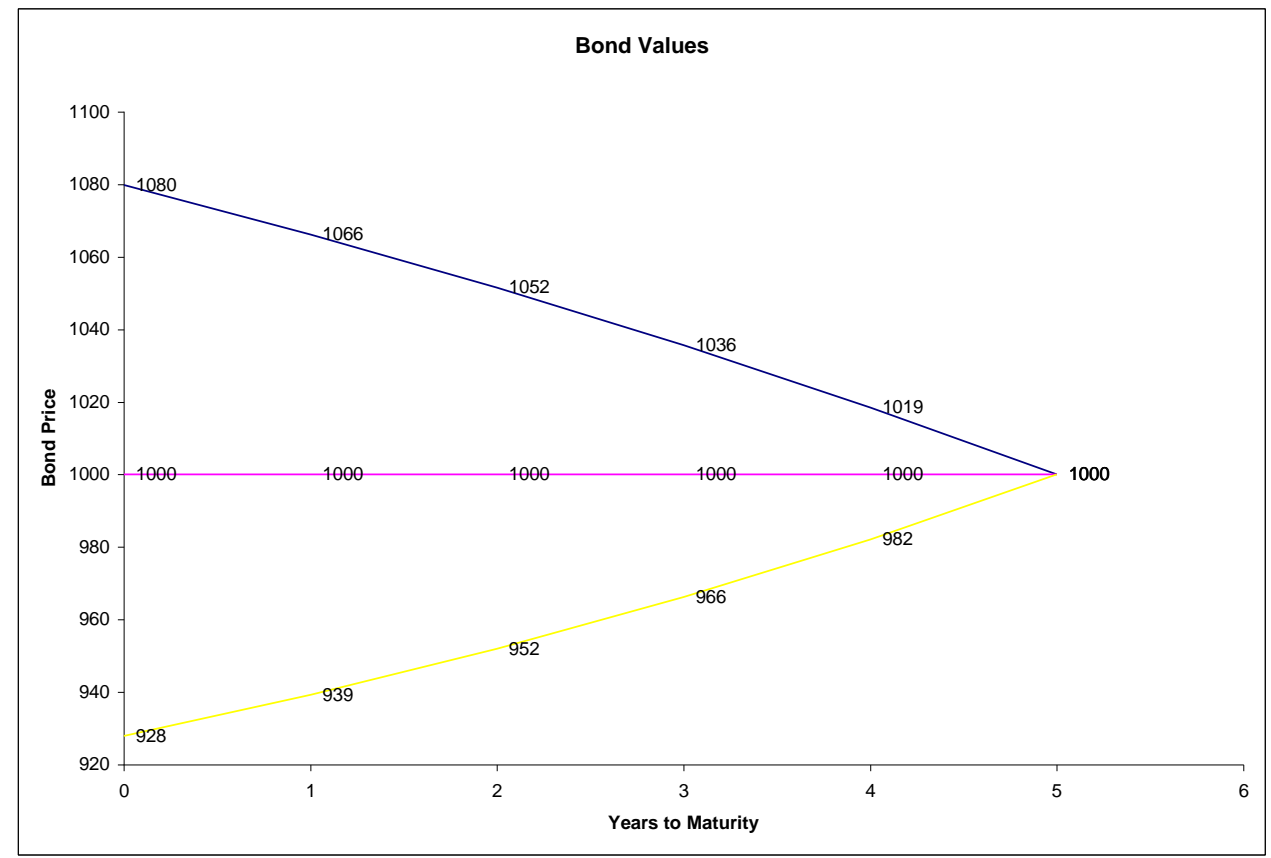

Figure 2. Bond Values at Various Discount Rates and Years to Maturity

There are only four coupon payments remaining and the maturity value is discounted four times. The value of the $\$ 1000$ terminal value increases to $\$ 735$ and the value of the four remaining coupons payments drops to $\$ 331$.

Calculate the bond price if we go forward in time one more year. Now, the term to maturity is only three years.

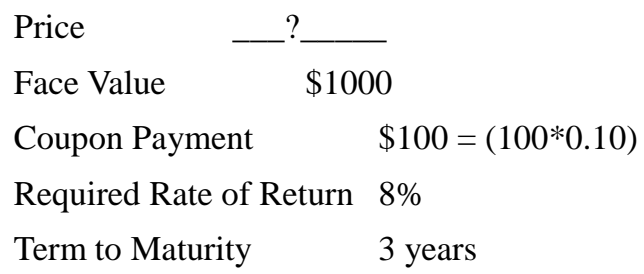

When we compute the price of the bond with three years to maturity, the price is $\$ 1052$. The coupon rate remains fixed at $10 \%$ and the yield to maturity is $8 \%$. Although nothing changed except the term to maturity, the price dropped. There are only three coupon payments remaining, and the maturity value is discounted three times. The value of the $\$ 1000$ terminal value increases to $\$ 794$ and the value of the four remaining coupons payments drops to $\$ 258$.

Calculate the bond price if we go forward in time one more year. Now, the term to maturity is only two years.

$\begin{array}{ll}\text { Price } & \text { Face Value } \\ \text { Coupon Payment } & 100=(100 * 0.10) \\ \text { Required Rate of Return } & 8 \% \\ \text { Term to Maturity } & 2 \text { years }\end{array}$

When we compute the price of the bond with two years to maturity, the price is $\$ 1036$. The coupon rate remains fixed at $10 \%$ and the yield to maturity is $8 \%$. Although nothing changed except the term to maturity, the price dropped. There are only three coupon payments remaining, and the maturity value is discounted three times. The value of the $\$ 1000$ terminal value increases to $\$ 857$ and the value of the four remaining coupons payments drops to $\$ 178$.

Calculate the bond price if we go forward in time one more year. Now, the term to maturity is only one years.

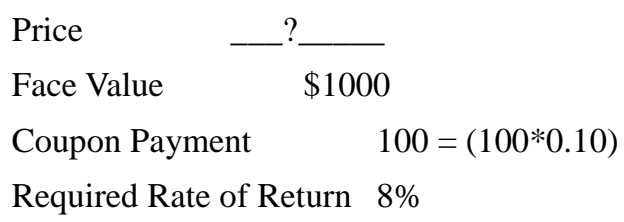




\section{Term to Maturity 1 years}

When we compute the price of the bond with two years to maturity, the price is $\$ 1019$. The coupon rate remains fixed at $10 \%$ and the yield to maturity is $8 \%$. Although nothing changed except the term to maturity, the price dropped. There are only three coupon payments remaining, and the maturity value is discounted three times. The value of the $\$ 1000$ terminal value increases to $\$ 926$ and the value of the four remaining coupons payments drops to $\$ 93$.

Calculate the bond price if we go forward in time one more year, at maturity. Now, the term to maturity is zero.

$\begin{array}{ll}\text { Price } & ?+\frac{?}{\text { Face Value }} \quad \$ 1000 \\ \text { Coupon Payment } & \$ 100=(100 * 0.10) \\ \text { Required Rate of Return } & 8 \% \\ \text { Term to Maturity } & 0 \text { years }\end{array}$

When we compute the price of the bond with two years to maturity, the price is $\$ 1000$. The coupon rate remains fixed at $10 \%$ and the yield to maturity is $8 \%$. Although nothing changed except the term to maturity, the price dropped.

There are no coupon payments remaining, and the maturity value is not discounted at maturity. The value of the $\$ 1000$ terminal value increases to $\$ 1000$ and the value of the coupons payments drops to $\$ 0$.

If a bond has a coupon rate that is greater than the required rate of return, the price will rise. The premium will decrease over time if the required rate of return stays the same. Thus, the price of this bond dropped from $\$ 1080$ with five years to maturity to the maturity value of $\$ 1000$, at maturity.

Table 3. Bond Values for a Bond Selling at a Discount. This first table shows the values computed for the example bond at a $12 \%$ yield to maturity.

\begin{tabular}{|c|c|c|c|c|c|}
\hline Face Value & & 1000 & & & \\
\hline Coupon Rate & & $10 \%$ & & & \\
\hline Years of Maturity & & 5 & & & \\
\hline Discount Rate & & $12 \%$ & & & \\
\hline \multirow[t]{7}{*}{ YTM } & & & $\mathrm{PV}(\mathrm{CP})$ & & \\
\hline & 5 & 567 & & 360 & 928 \\
\hline & 4 & 636 & & 304 & 939 \\
\hline & 3 & 712 & & 240 & 952 \\
\hline & 2 & 797 & & 169 & 966 \\
\hline & 1 & 893 & & 89 & 982 \\
\hline & 0 & 1000 & & 0 & 1000 \\
\hline
\end{tabular}

Now, assume that the moment that the bond is issued, the required rate of return for a bond with the same risk characteristics as this bond now requires a yield of $12 \%$. These values are summarized in table 3 . Calculate the bond price, if we go forward in time one year at a time. Now, the term to maturity is only five years.

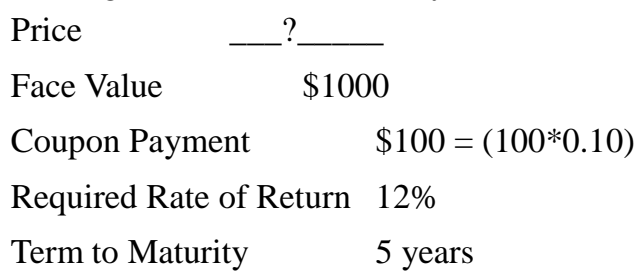

When we compute the price of the bond with a $12 \%$ yield to maturity and five years to maturity, the price is $\$ 928$. The value of the $\$ 1000$ terminal value is $\$ 567$ and the value of the five coupon payments of $\$ 100$ each is $\$ 361$. The price declines from $\$ 1000$ to $\$ 928$ because bond holders now require a $\$ 120$ per year coupon payment and our bond pays $\$ 100$ coupon per year. Thus, the demand for our bond will decrease and the price will decrease until the yield to maturity for our bond props from $10 \%$ to $12 \%$.

Calculate the bond price, if we go forward in time one year. Now, the term to maturity is only four years and the required rate of return is $12 \%$. 


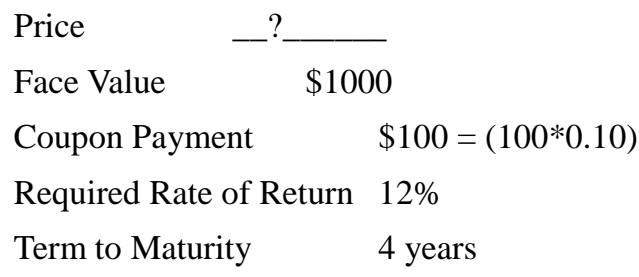

The coupon rate remains fixed at $10 \%$ and the yield to maturity is $12 \%$. When we compute the price of the bond with four years to maturity, the price is $\$ 939$. Although nothing changed except the term to maturity, the price increased. There are only four coupon payments remaining and the maturity value is discounted four times. The value of the $\$ 1000$ terminal value increases to $\$ 635$ and the value of the four remaining coupons payments drops to $\$ 304$.

Calculate the bond price if we go forward in time one more year. Now, the term to maturity is only three years.

$\begin{array}{ll}\text { Price } & \text { Face Value } \\ \text { Coupon Payment } & \$ 100=(100 * 0.10) \\ \text { Required Rate of Return } & 12 \% \\ \text { Term to Maturity } & 3 \text { years }\end{array}$

When we compute the price of the bond with three years to maturity, the price is $\$ 952$. The coupon rate remains fixed at $10 \%$ and the yield to maturity is $12 \%$. Although nothing changed except the term to maturity, the price increased. There are only three coupon payments remaining, and the maturity value is discounted three times. The value of the $\$ 1000$ terminal value increases to $\$ 712$ and the value of the four remaining coupons payments drops to $\$ 240$.

Calculate the bond price if we go forward in time one more year. Now, the term to maturity is only two years.

$\begin{array}{ll}\text { Price } & \text { ? } \frac{\text { Face Value }}{\$ 1000} \\ \text { Coupon Payment } & \$ 100=(100 * 0.10) \\ \text { Required Rate of Return } & 12 \% \\ \text { Term to Maturity } & 2 \text { years }\end{array}$

When we compute the price of the bond with two years to maturity, the price is $\$ 966$. The coupon rate remains fixed at $10 \%$ and the yield to maturity is $12 \%$. Although nothing changed except the term to maturity, the price increased. There are only three coupon payments remaining, and the maturity value is discounted three times. The value of the $\$ 1000$ terminal value increases to $\$ 797$ and the value of the four remaining coupons payments drops to $\$ 169$.

Calculate the bond price if we go forward in time one more year. Now, the term to maturity is only one years.

$\begin{array}{ll}\text { Price } & ?-\frac{}{\text { Face Value }} \\ \text { Coupon Payment } & \$ 100=(100 * 0.10) \\ \text { Required Rate of Return } & 12 \% \\ \text { Term to Maturity } & 1 \text { years }\end{array}$

When we compute the price of the bond with two years to maturity, the price is $\$ 982$. The coupon rate remains fixed at $10 \%$ and the yield to maturity is $12 \%$. Although nothing changed except the term to maturity, the price increased. There are only three coupon payments remaining, and the maturity value is discounted three times. The value of the $\$ 1000$ terminal value increases to $\$ 893$ and the value of the four remaining coupons payments drops to $\$ 89$.

Calculate the bond price if we go forward in time one more year, at maturity. Now, the term to maturity is zero.

$\begin{array}{ll}\text { Price } & -? \\ \text { Face Value } & \$ 1000 \\ \text { Coupon Payment } & \$ 100=(100 * 0.10) \\ \text { Required Rate of Return } & 12 \% \\ \text { Term to Maturity } & 0 \text { years }\end{array}$

When we compute the price of the bond with two years to maturity, the price is $\$ 1000$. The coupon rate remains fixed at 
$10 \%$ and the yield to maturity is $12 \%$. Although nothing changed except the term to maturity, the price increased. There are no coupon payments remaining, and the maturity value is not discounted at maturity. The value of the $\$ 1000$ terminal value increases to $\$ 1000$ and the value of the coupons payments drops to $\$ 0$.

If a bond has a coupon rate that is greater than the required rate of return, the price will rise. The premium will decrease over time if the required rate of return stays the same. Thus, the price of this bond dropped from $\$ 1080$ with five years to maturity to the maturity value of $\$ 1000$, at maturity. Figure 2 shows the path of the price for a bond when the required rate of return remains the same, decreases, or increases. If the required rate of return increases just at issue, the bond price will decrease. If the required rate of return remains at $12 \%$, the bond discount will decrease over time and the bond price will increase.

Figure 2 shows the path of the price for a bond when the required rate of return remains the same, decreases, or increases. If the required rate of return increases just at issue, the bond price will decrease. If the required rate of return remains at $12 \%$, the bond discount will decrease over time and the bond price will increase. As time passes and the maturity date draws nearer, regardless of the required rate of return, the price of the bond under different scenarios will converge to $\$ 1000$.

This first table shows the values computed for the example bond at an $8 \%$ yield to maturity. The next three tables show the financial calculator inputs to compute the bond value, the value of the coupon payments and the value of the face value of $\$ 1000$.

\section{Summary and Conclusions}

In this paper, we demonstrate how to compute bond values to demonstrate the time value of money. We show how to calculate the value of a $10 \%$ bond with five years to maturity for $8 \%, 10 \%$, and $12 \%$ discount rates. In addition, we show the impact of various discount rates and years to maturity for both the maturity value of the bond and the interest payment stream. A graph of the initial value of the bond with five years to maturity is provided that demonstrates that the premium or discount of a bond decreases over time as the time to maturity decreases. This pedagogical note can be used in finance or accounting courses to teach the principles of the time value of money.

\section{References}

Brigham, Eugene F. and Michael C. Ehrhardt. (2008) Financial Management, Theory and Practice, Twelth Edition, Mason, OH: Thomson/Southwestern.

Damodaran, A. (2006). Applied Corporate Finance, Second Edition, New York: John Wiley\& Sons, Inc.

Ross, S. Randolph, A., Westerfield, W., \& Bradford, D. (2008) Fundamentals of Corporate Finance, Eighth Edition, New York: McGraw-Hill Irwin.

Warren, C. S., James M. R., \& Jonathan, E. D. (2012). Managerial Accounting, Twelth Edition, Independence , KY: Cengage Publishing Company.

\section{(cc) BY}

This work is licensed under a Creative Commons Attribution 3.0 License. 